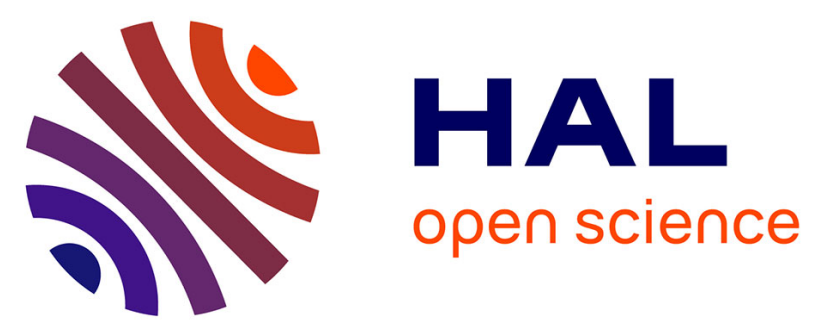

\title{
Incidence and patterns of meniscal tears accompanying the anterior cruciate ligament injury: possible local and generalized risk factors
}

\author{
Ashraf El Mansori, Timothy Lording, Antoine Schneider, Raphaël Dumas, \\ Elvire Servien, Sebastien Lustig
}

\section{To cite this version:}

Ashraf El Mansori, Timothy Lording, Antoine Schneider, Raphaël Dumas, Elvire Servien, et al.. Incidence and patterns of meniscal tears accompanying the anterior cruciate ligament injury: possible local and generalized risk factors. International Orthopaedics, 2018, 42 (9), pp. 2113-2121. 10.1007/s00264-018-3992-x . hal-01874008v2

\section{HAL Id: hal-01874008 \\ https://hal.science/hal-01874008v2}

Submitted on 8 Nov 2018

HAL is a multi-disciplinary open access archive for the deposit and dissemination of scientific research documents, whether they are published or not. The documents may come from teaching and research institutions in France or abroad, or from public or private research centers.
L'archive ouverte pluridisciplinaire HAL, est destinée au dépôt et à la diffusion de documents scientifiques de niveau recherche, publiés ou non, émanant des établissements d'enseignement et de recherche français ou étrangers, des laboratoires publics ou privés. 
Incidence and Patterns of Meniscal Tears Accompanying the Anterior Cruciate Ligament Injury: Possible Local and Generalized risk factors

\author{
Ashraf El Mansori ${ }^{1,2}$, Timothy Lording ${ }^{3}$, Antoine Schneider ${ }^{2}$, Raphael Dumas ${ }^{1}$, Elvire Servien ${ }^{2}$, \\ Sebastien Lustig $^{1,2}$ \\ ${ }^{1}$ Laboratoire de Biomécanique et Mécanique des Chocs, Université Claude Bernard Lyon 1 - \\ IFSTTAR, Villeurbanne, France \\ ${ }^{2}$ Orthopaedic Surgery Department, Lyon Croix Rousse University \\ Hospital, Lyon, France \\ ${ }^{3}$ Melbourne Orthopaedic Group, Melbourne, Australia
}




\section{ABSTRACT}

AIM OF THE WORK:

Injury to the anterior cruciate ligament $(A C L)$ is frequently accompanied by tears of the menisci. Some of these tears occur at the time of injury, but others develop over time in the $\mathrm{ACL}$ deficient knee. The aim of this study was to evaluate the effects of the patient characteristics, time from injury (TFI) and posterior tibial slope (PTS) on meniscal tear patterns. Our hypothesis was that meniscal tears would occur more frequently in ACL deficient knees with increasing age, weight, TFI, PTS, and in male patients.

\section{METHODS:}

$362 \mathrm{ACL}$ injured patients were analyzed, and details of meniscal lesions were collected. The medial and lateral tibial slopes (MTS, LTS) were measured via computed tomography. Patient demographics, TFI, MTS, and LTS were correlated with the diagnosed meniscal tears.

\section{RESULTS:}

113 patients had a medial meniscus (MM) tear, 54 patients had a lateral meniscus (LM) tear, 34 patients had tears of both menisci, and 161 patients had no meniscal tear. The most common tear location was the posterior horn $(\mathrm{PH})$ of the $\mathrm{MM}$, followed by tear involving the whole MM. Patient age, BMI, and TFI were significantly associated with the incidence of MM tear. Female patients had a higher incidence of injury than males in all tear sites except in the Body and PH. Male patients had more vertical and peripheral tears. The median MTS \& LTS for patients with $\mathrm{MM}$ tears were $7.0^{\circ}$ and $8.7^{\circ}$ respectively, while those of patients with LM tears were $6.9^{\circ}$ and $8.1^{\circ}$. Steeper LTS was significantly associated with tears of LM and of both menisci.

\section{CONCLUSION:}

Older age, male sex, increased BMI and prolonged TFI were significant factors for the development of MM tears. An increase in the tibial slope, especially of the lateral plateau, seems to increase the risk of tear of the LM and of both menisci.

LEVEL OF EVIDENCE: level III

KEY WORDS: Knee, ACL Injury, Meniscus tear, Tibial slope, Time from injury. 


\section{INTRODUCTION}

The anterior cruciate ligament $(A C L)$ is the primary restraint to anterior tibial translation (ATT), providing $85 \%$ of the total restraining force to anterior drawer [5]. Isolated ACL tears are uncommon, with approximately $50 \%$ accompanied by meniscal tears due to the close anatomic and functional relationships of these structures [10].

The menisci are important structures within the knee, with complex biomechanical functions. They are thought to carry $40-70 \%$ of the load across the knee, and they have a role in shock absorption, proprioception, and enhancement of stability [30].

Preservation of meniscal tissue and function is paramount for long-term joint function, especially in active patients. Early repair of tears of the posterior horn (PH) of the lateral meniscus (LM) significantly improve loading profiles in the lateral compartment, and may help to prevent the cartilage degeneration and osteoarthritis associated with partial meniscectomy [10].

Understanding the demographic and morphometric differences in ACL deficient patients with meniscal lesions becomes more important in injury prevention and treatment. Many studies have analyzed predictors of these injuries and demonstrated an association between meniscus tears and male sex, obesity, increased age, varus malalignment and increased time from injury (TFI) [7, 10, 12, 26, 31, 37].

A limitation of these studies is that meniscus tears were considered a binary finding (i.e. tear vs. no tear). However, different patterns of meniscal tears in $A C L$ injured subjects may be associated with different demographic and historical risk factors. Identification of such risk factors may help physicians recognize patients at risk of more significant or irreparable meniscal tears.

Furthermore, patients may present with knee pain and isolated meniscal tears, without any history of trauma, implying other causative factors. One may hypothesize that the bony morphology of the knee, including the posterior tibial slope (PTS), may contribute to the development of meniscal tears.

The purpose of this study to document the incidence and distribution of meniscal lesions accompanying $A C L$ tears in a large patient cohort, and to test for associations between these lesions and patient age, gender, Body Mass Index (BMI), time from injury (TFI) and medial and lateral tibial slope (MTS \& LTS).

Our hypothesis was that meniscal tears would occur more frequently in $A C L$ deficient knees with increasing age, weight, TFI, PTS, and in male patients. We further hypothesized that increased PTS and TFI would be associated with more significant meniscal lesions. 


\section{MATERIALS \& METHODS}

\section{STUDY DESIGN}

A retrospective cohort study was performed to analyze the association between different patterns of meniscal tears in ACL-injured subjects, and potential demographic and historical risk factors. As all data were collected retrospectively from medical records, Institutional Review Board approval was not required at our institution.

\section{PATIENTS SELECTION}

All patients undergoing $A C L$ reconstruction in our institution between 2012 and 2015 were recruited to this study.

The pre-operative clinical notes were reviewed to collect patient age, gender, BMI and TFI data.

The pre-operative clinical and radiological examination findings, as well as the intra-operative findings, were also reviewed. All data were recorded on evaluation forms.

Patients with either partial or complete ACL rupture in the affected knee, as established by arthroscopy, were included in the study. Exclusion criteria were patients less than 18 years old, a history of previous surgery involving partial meniscectomy, other ligamentous lesions, or signs of osteoarthritis.

Seven patients were also excluded due to incomplete or ambiguous documentation of meniscal status.

A total of 362 consecutive patients with partial or complete rupture of ACL injury were included, and were divided into 4 groups according to the involved meniscus; Group 1 with medial meniscal (MM) tear, Group 2 with lateral meniscal (LM) tear, Group 3 with tears of both menisci, and Group 4 with no meniscal tear.

\section{MENISCAL TEAR CLASSIFICATION}

In all patients, meniscal lesions were confirmed arthroscopically using a standard probe and documented according to the ISAKOS classification [2]. Tears were documented occurring in the medial or lateral meniscus. In addition, each meniscus was subdivided into three parts: the anterior horn, the body and the posterior horn.

We further categorized the type of meniscal tear as Vertical, Horizontal, Peripheral (Meniscocapsular \& Ramp lesions), Oblique, Flap, Radial or Complex. Other variations such as bucket-handle and degenerative tears were also recorded.

\section{TIBIAL SLOPE MEASUREMENT}

The archived computed tomography (CT) scan images were analyzed and morphometric measurements were performed using a picture archiving and communication system (PACS, Centricity, GE Healthcare, Waukesha, Wisconsin) workstation with standard features, including the ability to adjust windows, change the zoom, and apply electronic calipers. 
The MTS and the LTS were measured by two blinded radiologists using the modified midpoint method previously published by Lustig et al. [24]. Three sagittal slices were selected corresponding to the midsagittal, the mid-medial compartment sagittal (B), and the midlateral compartment sagittal cut (C) (Fig. 1). All sagittal slices were selected manually, and digital measurements were performed twice for each patient two weeks apart to assess the intra-observer reliability.

The proximal tibial anatomical axis (PTAA) was selected to establish the PTS. This axis has been shown to have the best correlation with the tibial shaft anatomic axis and reflect most accurately the mechanical axis of the tibia [39].

The PTAA was established on the mid-sagittal cut by a line joining the midpoint between the anterior and posterior tibial cortices at the level of the tibial tuberosity and at another level 5 $\mathrm{cm}$ more distal. The angle subtended between the tibial axis to the horizontal was then calculated (PTTA-H Angle) (Fig. 2). This angle was then used to transfer the calculated tibial axis to the medial and lateral sagittal cuts to assess the MTS and LTS respectively. The tibial slope in each compartment were measured as the angle between a line perpendicular to PTAA and a line connecting the superior points of the anterior and posterior corresponding tibial plateau (Fig. 3). A posterior inclination was assigned a positive value, while an anterior inclination was assigned a negative value.

\section{STATISTISTICAL ANALYSIS}

Statistical analysis was performed using SPSS for Windows (version 11.5; SPSS, Chicago, IL, USA). Microsoft Excel was used to calculate statistical values and to create diagrams. Continuous variables were calculated as mean \pm standard deviation and categorical variables were reported as count and percentages. The assumption of normality was assessed with Kolmogorov-Smirnov tests. Inter and Intra-observer reliabilities were tested by means of Intra Class Correlation Coefficients (ICC). The Wilcoxon rank sum test and the Chi2 test were used to test the difference between the continuous and categorical variables. Kruskal-Wallis ANOVA test and post-hoc tests were used to test the effects age, sex, BMI, TFI, MTS and LTS on the incidence, sites and types of meniscal tears. The results of correlations and risk analysis were calculated separately, where the probability of this result, assuming the null hypothesis, was less than 0.05 . 


\section{RESULTS}

The distribution of age, BMI, LTS, MTS and TFI were tested using a one-sample KolmogorovSmirnov test. All variables were normally distributed except TFI $(p<0.001)$.

The means, standard deviations (SD) and ranges are shown in Table (1).

DISTRIBUTION OF MENISCAL LESIONS:

From 362 patients ( 238 male and 124 female), there were 113 patients with an isolated MM tear (group 1), 54 patients with an isolated LM tear (group 2), 34 patients with tears of both menisci (group 3), and 161 patients with no meniscal tear (group 4) (Fig. 4).

The most common tear location of the MM was the posterior horn (PH), followed by tears of the whole meniscus. Similarly, tears of the LM tended to be distributed more posteriorly and involve mainly the $\mathrm{PH}$, followed by the tears involving both the $\mathrm{PH}$ and body. Tears of the anterior parts of the menisci were seen least frequently. The distribution of meniscal tears across the different anatomical regions is shown in Figure 5.

TYPES OF MM TEARS (Groups 1\&3):

After evaluating all $147 \mathrm{MM}$ tears, the most common tear type was a vertical tear (33\%), followed by bucket-handle tears (18\%). We noted an equal proportion of peripheral and complex tears ( $12 \%$ each), while the degenerative tears represented the least common type (1\%) (Fig. 6a).

TYPES OF LM TEARS (Groups 2\&3):

In 88 LM tears, vertical tears were observed in 27. In comparison with MM tears, there were less of bucket-handle tears (5\%) but more horizontal tear amongst the LM tears than the MM $(18 \%$ vs. $6 \%)$. As in the $\mathrm{MM}$, the degenerative tears represented the least tear type $(2 \%)$. Oblique tears had the same distribution for both sides (6\%) (Fig. 6b).

\section{PATIENT AGE}

The median age of the patients with MM tears was 32.9 years while that of patients with LM tears was 29.7 (ns).

There were a significant relationship between patient age and the incidence of MM tears, with older patients having more MM tears $(p=0.002)$. However, there was no such relationship for the other groups.

\section{GENDER}

Using Chi2 test, there were significant associations between sex and the incidence of MM tears $(p=0.034)$, the incidence of the LM tears $(p=0.002)$, and the incidence of both menisci tears $(p=0.005)$. Male patients predominated in all groups. The percentages of male and female patients having these tears were $44.5 \%$ and $33.1 \%(\mathrm{MM}), 28.1 \%$ and $14.5 \%(\mathrm{LM})$, and $12.2 \%$ and $3.2 \%$ (both) respectively. 
We also found a significant associations between sex and tear sites $(p=0.002)$. Female patients had a higher incidence of injury to all tear sites except the Body and posterior horn, and posterior horn tears. The percentages of male and female patients having tears in the different sites were $1.8 \%$ and $2.4 \%$ for anterior horn tears, $0.9 \%$ and $2.4 \%$ for body tears, $16.0 \%$ and $12.2 \%$ for posterior horn and body tears, $70.7 \%$ and $43.9 \%$ for posterior horn tears, and $10.4 \%$ and $39.0 \%$ for entire meniscus tears respectively.

Finally we found an association between sex and the type of the meniscal tear $(p<0.001)$. Male patients had more vertical, peripheral, and oblique tears, while females had a higher percentage of horizontal, flap, bucket-handle, degenerative, radial and complex tears. The distribution of the tear types between male and female patients are shown in Table (2).

BMI

The median BMI for the patients with MM tears was 24.2 while that of patients with $\mathrm{LM}$ tears was 23.8 (ns). BMI had a significant effect on the incidence of MM tears ( $p=0.029)$, with patients with higher BMI having a higher incidence. Conversely, no effect of the BMI on the incidence of meniscus tears in the other groups. BMI did not affect the tear sites or types in any groups.

\section{TIME FROM INJURY}

The median TFI for patients with MM tears was 5.9 months while that for patients with LM tears was 4.7 months (ns).

TFI had a significant effect on the incidence of MM tears, with patients having a longer time to surgery more likely to have MM tears at the time of surgery $(p=0.031)$. Similar results were seen in group 2, however, this did not reach statistical significance $(p=0.056)$.

TFI did not influence tear site or type, with the exception of MM tear types. In this group, the Dunn and Sidák's post hoc test revealed that TFI was significantly higher for radial type (median $=18.73$ ) than for peripheral (4.53) and oblique (3.55) types $(p=0.022)$.

\section{TIBIAL SLOPE}

Repeated measures analysis of variance showed strong agreement between the two raters for both the medial and lateral slopes (ICC 0.83 and 0.88 for MTS \&LTS respectively). Intraobserver reliability was also high for all measurements (0.89-0.93).

The median MTS and LTS for patients with MM tears were $7.0^{\circ}$ and $8.7^{\circ}$ respectively while those for patients with $L M$ tears were $6.9^{\circ}$ and $8.1^{\circ}$, respectively (ns).

The LTS has a significant effect on the incidence of LM tears. Patients with LM tears demonstrated greater LTS (median $\left.=9.5^{\circ}\right)$ compared to that of patients without tears $\left(7.2^{\circ}\right)(p$ $=0.003$ ). Similarly, the LTS has a significant effect on the incidence of both menisci tears (group $3)$, with patients in this group demonstrating greater LTS $\left(9.3^{\circ}\right)$ compared to that of the patients without tears $\left(7.5^{\circ}\right)(p=0.007)$. The MTS did not influence the incidence of meniscus tears in any groups. Neither the MTS nor the LTS had an effect on the tear site or type in any group. 


\section{DISCUSSION}

The overall incidence of meniscal tears in the present study was 55\% (31\% for MM, 15\% for LM and $9 \%$ for both menisci). This finding is consistent with rates in the literature $[14,26$, 31]. Various mechanisms affect the frequency of medial and lateral meniscal tears, including lower limb alignment, load distribution, and delay of intervention. The incidence of LM tears remained relatively unchanged with time, while MM tears increased with time.

Biomechanically, the $\mathrm{MM}$ is a secondary stabilizer of the knee against anterior displacement of the tibia in the ACL-injured knee, and is subjected to anteroposterior shear forces. On the other hand, the more mobile LM is less likely to undergo these shear stresses [23]. This may account for the high incidence of MM tears, but further studies are necessary to prove this theory.

The most common tear location in the $\mathrm{MM}$ in our study was the $\mathrm{PH}$ with the most common tear types being vertical tears was (33\%), followed by bucket-handle tears (18\%) and peripheral tears (12\%). These findings in accordance with the current literature [35]. More bucket-handle tears were seen in the MM than in the LM. These findings are consistent with other studies which found that MM tears were likely to be bucket-handle type regardless of the chronicity of the injury [14, 15]. Cerabona et al. have theorized that the recurrent trauma sustained by the MM while acting as a cushion in the ACL-deficient knee leads to $\mathrm{PH}$ tears [6]. This may be due to its relative immobility, resulting in a decreased ability to absorb shear stresses during subluxation of the tibial plateau during the pivot shift [30].

Regarding LM tears, the most common site for the tears was also the posterior horn. The most common tear types were vertical (27\%) and horizontal tears (18\%).

Radial tears were also more common in the LM (12\% vs. $8 \%$ ). It has been reported that approximately $15 \%$ of meniscal tears are radial tears, with $20 \%$ of these tears occurring in the $\mathrm{PH}$ of the LM, which may be more susceptible to radial tears due to a lack of ligamentous support [16]. Choi et al. reported that more radial tears were found in female patients than horizontal tears [8].

Radial tears of the meniscus significantly impair the load-bearing function of the meniscus and cause the meniscus to be extruded under axial loads. If the meniscus is displaced, the incongruent bony articular surfaces come in direct contact, and subsequent damage to the articular cartilage will occur [4].

In our study, the LM showed more flap tears than the MM (7\% vs. $4 \%$ ). These results are supported by those of Ghodadra et al., who found that the full-thickness LM tears were more often flap-type tears [14].

Several factors are reported to increase the risk of meniscal tears in ACL-deficient patients. These include older age, male gender, increased bodyweight, time from injury, and repetitive activities [10, 12, 28, 29, 37].

We found increasing age to be associated with increased medial but not lateral meniscal tears regardless of location of tear. For the different lesion types, the age seemed homogenous. In 
contrast, Feucht et al. observed higher risk for LM tears in younger patients [10], and other authors have found no correlation between age and meniscal injury [38].

There is general belief of a strong effect of aging on the menisci in the literature. These effects may include vascular changes [32], biochemical changes [36], and degenerative changes [18]. The patients in our study, however, were relatively young, and degenerative tears were uncommon.

We also observed increased meniscal injury in male patients across all groups. Other authors, however, have found no such association [11]. Male patients had a higher incidence of injury in the body and posterior horn of both menisci and show more vertical, peripheral tears than females. This observed injury pattern may be explained by a lesser degree of $A C L$ resilience in women, leading to $A C L$ rupture at smaller forces with less associated meniscal injury [33]. On other hand, the patterns could be due to less resilient meniscal tissue and contraction difference in quadriceps or hamstring muscles in males [17]. Further investigation is needed to clarify the tissue-level influence on this potential gender difference.

In our study, increased BMI was also associated with an increased incidence of MM tears. Generally, obesity has an unfavorable effect on the knee joint, and previously BMI and weight equally predicted meniscal injury [3]. Consequently, Ford et al. [12] reported a significant correlation between meniscal tear and increasing BMI.

Chen, however, found no correlation between BMI and meniscal or chondral injury, and suggested that higher BMI patients may be less active and thus less at risk for further injury [7]. There is a potential biomechanical explanation for the relationship between BMI and meniscal tears, in that as the BMI increases, the torque in the knee joint during rotation may increase, and theoretically may cause more meniscal injury [8].

Increased interval between injury and surgery has also been shown to increase the frequency and severity of meniscal injuries [11].

Our study confirms that a delay in surgical treatment is associated with a higher incidence of $\mathrm{MM}$ tears. Our results are in accordance with the results of other studies that reported an increased incidence of MM tears in chronic (70-78 \%) compared to acute injuries (30 - 45\%) $[9,19,20,28]$. Similarly, our study supports previous reports that LM tears remain fairly constant in respect to TFI $[9,11,13]$. These findings support the notion that most LM tears occur at the time of injury during the subluxation of the lateral compartment, while further $\mathrm{MM}$ tears occur due to the role of the MM as a secondary stabilizer in the $\mathrm{ACL}$ deficient knee. Anatomically, the MM is attached firmly to the joint capsule and also adherent to the inferior margin of the tibial plateau by the coronary ligament which may account for the increased incidence of MM tears in chronically ACL deficient knees.

Recently, a number of studies have investigated the association between the geometry of the proximal tibia and the risk of $\mathrm{ACL}$ injury $[1,22,25]$, however, little information on the relationship between tibial slope and meniscal tear is available. In theory, a greater PTS will cause more anterior tibial translation under load, which may increase the forces in both the $\mathrm{ACL}$ and the menisci. More specifically in the lateral compartment, increased slope may cause a rotatory moment under load [34], to which the lateral meniscus is a stabilizer [27]. 
Markl et al. examined the rate of meniscal tears in found $A C L$ deficient patients and noted increased rates of meniscal tears in with medial and lateral tibial slope greater than $10^{\circ}$ (odds ratio 2.11 for medial and 3.44 for lateral slope), however in this small study of only 71 subjects these findings did not reach statistical significance [25].

In the present study, the LTS was greater in the knees with LM or both menisci tears compared to that of patients without tears, but the MTS was similar in knees with and without MM tears. In contrast, Khan et al. observed a significant association between shallower MTS and tears of the PH of the MM. They hypothesized that entrapment of the PH horn of MM within a tight medial compartment could occur as a result of the shallower MTS [21].

We suggest that PTS is one of the considerations in $A C L$ injury to prevent secondary meniscal tears in patients with $A C L$ injury. Increased slope, particularly in the lateral compartment, is a risk factor for lateral and both menisci tears, and when identified should prompt the clinical to consider early $\mathrm{ACL}$ reconstruction to prevent further meniscal injury.

The present study has several limitations. Firstly, the retrospective design of the study is an inherent limitation, as the clinical report was sometimes imprecise concerning the description of meniscal lesions.

Furthermore, this study focused on limited risk factors. We did not evaluate factors such as activity level or lower limb alignment which may affect the severity of meniscal injury in $\mathrm{ACL}$ injured patients.

Further prospective studies with greater sample sizes are needed to better understand the relationship between these parameters and tear types and sites. Biomechanical and kinematic studies are needed to further explore the association between tibial slope and meniscal tears.

\section{CONCLUSION}


Older age, male sex, increased $\mathrm{BMI}$ and prolonged TFI were significant factors for the development of MM tears. An increase in the tibial slope, especially of the lateral plateau, seems to increase the risk of tear of the LM and of both menisci. Therefore, it may be suggested that tibial slope could be one parameter to consider in ACL injured patients for recommending early reconstruction, in order to prevent secondary meniscal tears.

Funding : There is no funding source.

\section{Compliance with ethical standards :}

\section{Conflict of interest}

$A E, T L, A S, R D$ : no conflict of interest.

ES: consultant for Smith \& Nephew, institutional research support from Corin and Amplitude.

SL: consultant for Smith \& Nephew, institutional research support from Corin and Amplitude.

\section{Ethical approval :}

All procedures performed in studies involving human participants were in accordance with the ethical standards of the institutional and/or national research committee and with the 1964 Declaration of Helsinki and its later amendments or comparable ethical standards. For this type of study, formal consent is not required.

\section{REFERENCES}


1- Alici T, Esenyel CZ, Esenyel M, Imren Y, Ayanoglu S, Cubuk R. (2011) Relationship between meniscal tears and tibial slope on the tibial plateau. Eurasian J Med. 43(3):146151.

2- Anderson AF, Irrgang JJ, Dunn W, Beaufils P et al. (2011) Interobserver reliability of the International Society of Arthroscopy, Knee Surgery and Orthopaedic Sports Medicine (ISAKOS) classification of meniscal tears. Am J Sports Med. 39(5):926-932.

3- Bowers AL, Spindler KP, McCarty EC, Arrigain S. (2005) Height, weight, and BMI predict intra-articular injuries observed during $A C L$ reconstruction: evaluation of 456 cases from a prospective ACL database. Clin J Sport Med. 15(1):9-13.

4- Boyd KT, Myers PT. (2003) Meniscus preservation: rationale, repair techniques and results. Knee. 10(1):1-11

5- Butler DL, Noyes FR, Grood ES. (1980) Ligamentous restraints to anterior-posterior drawer in the human knee: a biomechanical study. J Bone Joint Surg Am. 62(2):259-270.

6- Cerabona F, Sherman MF, Bonamo JR, Sklar J. (1988) Patterns of meniscal injury with acute anterior cruciate ligament tears. Am J Sports Med. 16(6):603-609.

7- Chen G, Tang X, Li Q, Zheng G, Yang T, Li J. (2015) The evaluation of patient-specific factors associated with meniscal and chondral injuries accompanying $A C L$ rupture in young adult patients. Knee Surg Sports Traumatol Arthrosc. 23(3):792-798.

8- Choi CJ, Choi YJ, Song IB, Choi CH. (2011) Characteristics of Radial Tears in the Posterior Horn of the Medial Meniscus Compared to Horizontal Tears. Clin Orthop Surg. 3(2):128132.

9- Church S, Keating JF. (2005) Reconstruction of the anterior cruciate ligament: timing of surgery and the incidence of meniscal tears and degenerative change. J Bone Joint Surg Br. 87(12):1639-1642.

10- Feucht MJ, Bigdon S, Bode G, Salzmann GM, Dovi-Akue D, Südkamp NP, Niemeyer P. (2015) Associated tears of the lateral meniscus in anterior cruciate ligament injuries: risk factors for different tear patterns. J Orthop Surg Res. 10:34.

11- Fok AW, Yau WP. (2013) Delay in ACL reconstruction is associated with more severe and painful meniscal and chondral injuries. Knee Surg Sports Traumatol Arthrosc. 21(4):928933.

12- Ford GM, Hegmann KT, White GL Jr, Holmes EB. (2005) Associations of body mass index with meniscal tears. Am J Prev Med. 28(4):364-368. 
13- Gadeyne S, Besse JL, Galand-Desme S, Lerat JL, Moyen B. (2006) Analysis of meniscal lesions accompanying anterior cruciate ligament tears: A retrospective analysis of 156 patients. Rev Chir Orthop Reparatrice Appar Mot. 92(5):448-454.

14- Ghodadra N, Mall NA, Karas V, Grumet RC, Kirk S, McNickle AG, Garrido CP, Cole BJ, Bach BR Jr. (2013) Articular and Meniscal Pathology Associated with Primary Anterior Cruciate Ligament Reconstruction. J Knee Surg. 26(3):185-193.

15- Guenther ZD, Swami V, Dhillon SS, Jaremko JL. (2014) Meniscal Injury After Adolescent Anterior Cruciate Ligament Injury: How Long Are Patients at Risk?. Clin Orthop Relat Res. 472(3):990-997.

16- Harper KW, Helms CA, Lambert HS 3rd, Higgins LD. (2005) Radial meniscal tears: significance, incidence, and MR appearance. AJR Am J Roentgenol. 185(6):1429-1434.

17- Huston $\amalg$, Wojtys EM. (1996) Neuromuscular performance characteristics in elite female athletes. Am J Sports Med. 24(4):427-436.

18- Jerosch J, Castro WHM, Assheuer J.(1996) Age-related magnetic resonance imaging morphology of the menisci in asymptomatic individuals. Arch Orthop Trauma Surg. 115(3-4):199-202.

19- Joseph C, Pathak SS, Aravinda M, Rajan D. (2008) Is ACL reconstruction only for athletes? A study of the incidence of meniscal and cartilage injuries in an ACL-deficient athlete and non-athlete population: an Indian experience. Int Orthop. 32(1):57-61.

20- Keene GC, Bickerstaff D, Rae PJ, Paterson RS. (1993) The natural history of meniscal tears in anterior cruciate ligament insufficiency. Am J Sports Med. 21(5):672-679.

21- Khan N, McMahon P, Obaid H. (2014) Bony morphology of the knee and non-traumatic meniscal tears: Is there a role for meniscal impingement?. Skeletal Radiol. 43(7):955962.

22-Lee JJ, Choi YJ, Shin KY, Choi CH. (2011) Medial meniscal tears in anterior cruciate ligament-deficient knees: effects of posterior tibial slope on medial meniscal tear. Knee Surg Relat Res. 23(4):227-230.

23- Levy IM, Torzilli PA, Warren RF (1982) The effect of medial meniscectomy on anteriorposterior motion of the knee. J Bone Joint Surg Am 64(6):883-888.

24- Lustig S, Scholes CJ, Leo SP, Coolican M, Parker DA. (2013) Influence of soft tissues on the proximal bony tibial slope measured with two-dimensional MRI. Knee Surg Sports Traumatol Arthrosc. 21:372-379.

25- Markl I, Zantop T, Zeman F, Seitz J, Angele P. (2015) The effect of tibial slope in acute ACL-insufficient patients on concurrent meniscal tears. Arch Orthop Trauma Surg. 135(8):1141-1149. 
26- Michalitsis S, Vlychou M, Malizos KN, Thriskos P, Hantes ME. (2015) Meniscal and articular cartilage lesions in the anterior cruciate ligament-deficient knee: correlation between time from injury and knee scores. Knee Surg Sports Traumatol Arthrosc. 23(1):232-239.

27- Musahl V, Citak M, O'Loughlin PF, Choi D, Bedi A, Pearle AD. (2010) The effect of medial versus lateral meniscectomy on the stability of the anterior cruciate ligament-deficient knee. Am J Sports Med. 38(8):1591-1597.

28- O'Connor DP, Laughlin MS, Woods GW. (2005) Factors related to additional knee injuries after anterior cruciate ligament injury. Arthroscopy. 21(4):431-438.

29- Paletta GA Jr, Levine DS, O'Brien SJ, Wickiewicz TL, Warren RF. (1992) Patterns of meniscal injury associated with acute anterior cruciate ligament injury in Skiers. Am J Sports Med. 20(5):542-547.

30- Papageorgiou CD, Gil JE, Kanamori A, Fenwick JA, Woo SL, Fu FH. (2001) The biomechanical interdependence between the anterior cruciate ligament replacement graft and the medial meniscus. Am J Sports Med 29(2):226-231.

31- Papastergiou SG, Koukoulias NE, Mikalef P, Ziogas E, Voulgaropoulos H. (2007) Meniscal tears in the ACL-deficient knee: correlation between meniscal tears and the timing of ACL reconstruction. Knee Surg Sports Traumatol Arthrosc. 15(12):1438-1444.

32- Petersen W, Tillmann B.(1995) Age-related blood and lymph supply of the knee menisci: a cadaver study. Acta Orthop Scand. 66(4):308 -312.

33- Piasecki DP, Spindler KP, Warren TA, Andrish JT, Parker RD. (2003) Intraarticular injuries associated with anterior cruciate ligament tear: findings at ligament reconstruction in high school and recreational athletes. An analysis of sex-based differences. Am J Sports Med. 31(4):601-605.

34- Simon RA, Everhart JS, Nagaraja HN, Chaudhari AM. (2010) A case-control study of anterior cruciate ligament volume, tibial plateau slopes and intercondylar notch dimensions in ACL-injured knees. J Biomech. 43(9):1702-1707.

35-Smith JP, Barrett GR. (2001) Medial and lateral meniscal tear patterns in anterior cruciate ligament-deficient knees. A prospective analysis of 575 tears. Am J Sports Med. 29(4):415-419.

36- Takahashi M, Suzuki M, Kushida K, Hoshino H, Inoue T. (1998) The effect of aging and osteoarthritis on the mature and senescent cross-links of collagen in human meniscus. Arthroscopy. 14(4):366 -372.

37- Tandogan RN, Taşer O, Kayaalp A, Taşkiran E, Pinar H, Alparslan B, Alturfan A. (2004) Analysis of meniscal and chondral lesions accompanying anterior cruciate ligament 
tears: relationship with age, time from injury, and level of sport. Knee Surg Sports Traumatol Arthrosc. 12(4):262-270.

38- Yüksel HY, Erkan S, Uzun M. (2006) The evaluation of intraarticular lesions accompanying ACL ruptures in military personnel who elected not to restrict their daily activities: the effect of age and time from injury. Knee Surg Sports Traumatol Arthrosc. 14(11):11391147.

39- Zhang Y, Wang J, Xiao J, Zhao L, Li ZH, Yan G, Shi ZJ. (2014) Measurement and comparison of tibial posterior slope angle in different methods based on three-dimensional reconstruction. The Knee. 21(3):694-698. 


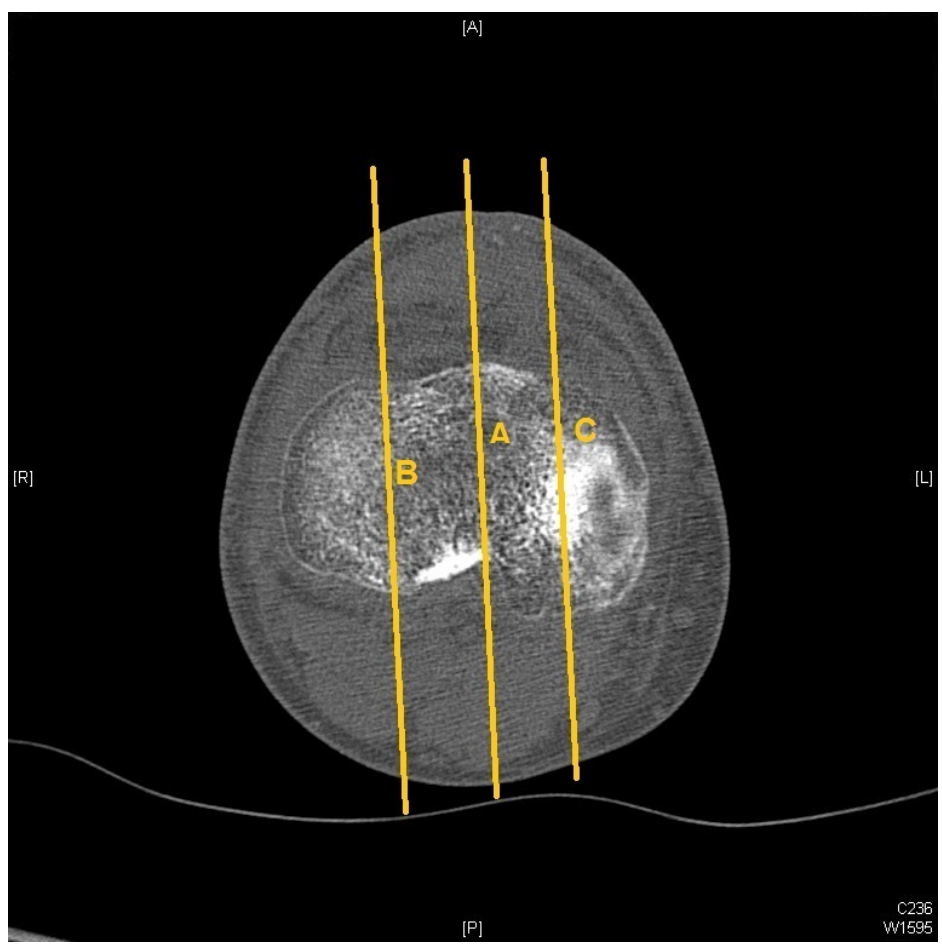

Fig.1: Three $C T$ axial cuts of the tibia at superior joint line were taken to select the corresponding midsagittal (A), the mid-medial sagittal (B), and the mid-lateral sagittal images (C). 




Fig.2: The PTTA was defined as a line through the midpoints between the two tibial cortices at the level of tibial tuberosity and at $5 \mathrm{~cm}$ more distal. The angle between the PTAA and the horizontal was also calculated (PTTA-H). 


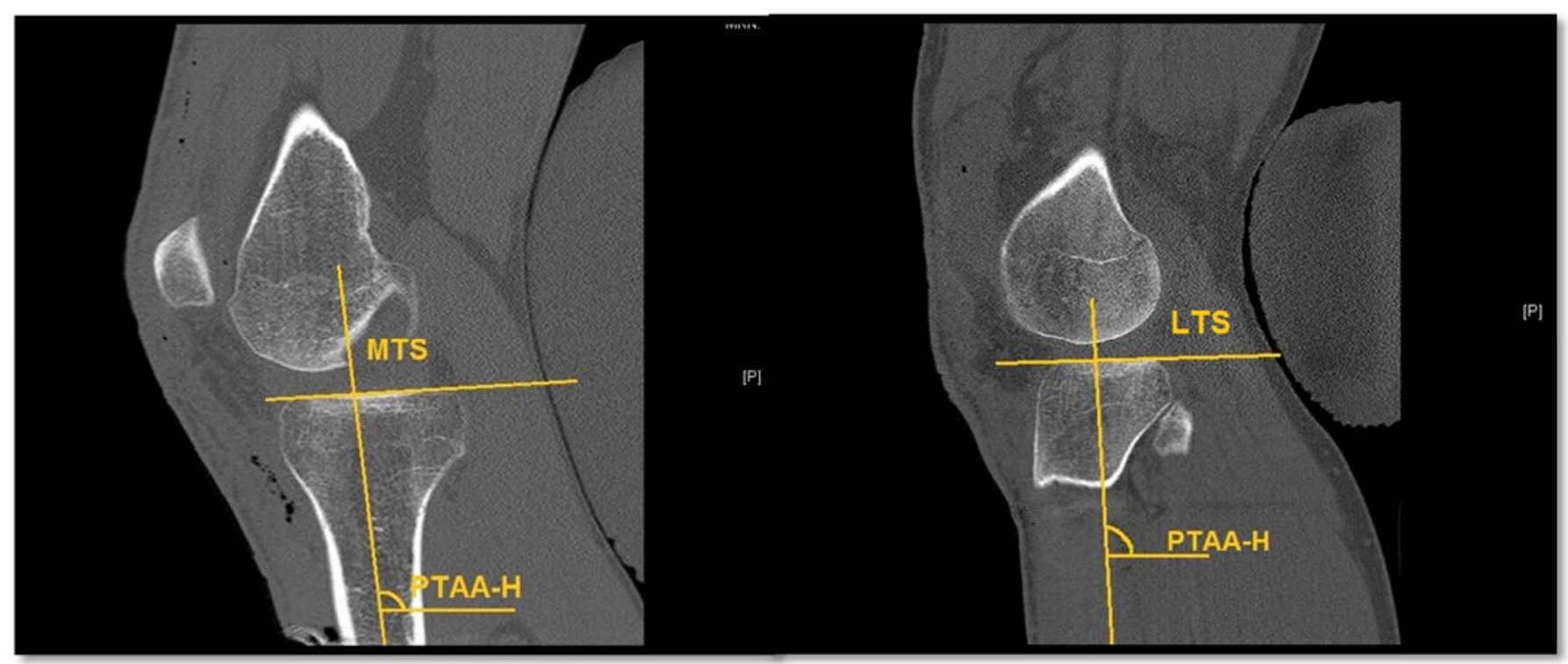

Fig. 3: Superimposition of the PTTA on each corresponding sagittal image by means of PTAA-

H. Calculation of the MTS \&LTS as the angle between a line joining the high points of the anterior \& posterior tibial plateau and a line perpendicular to the PTTA. 


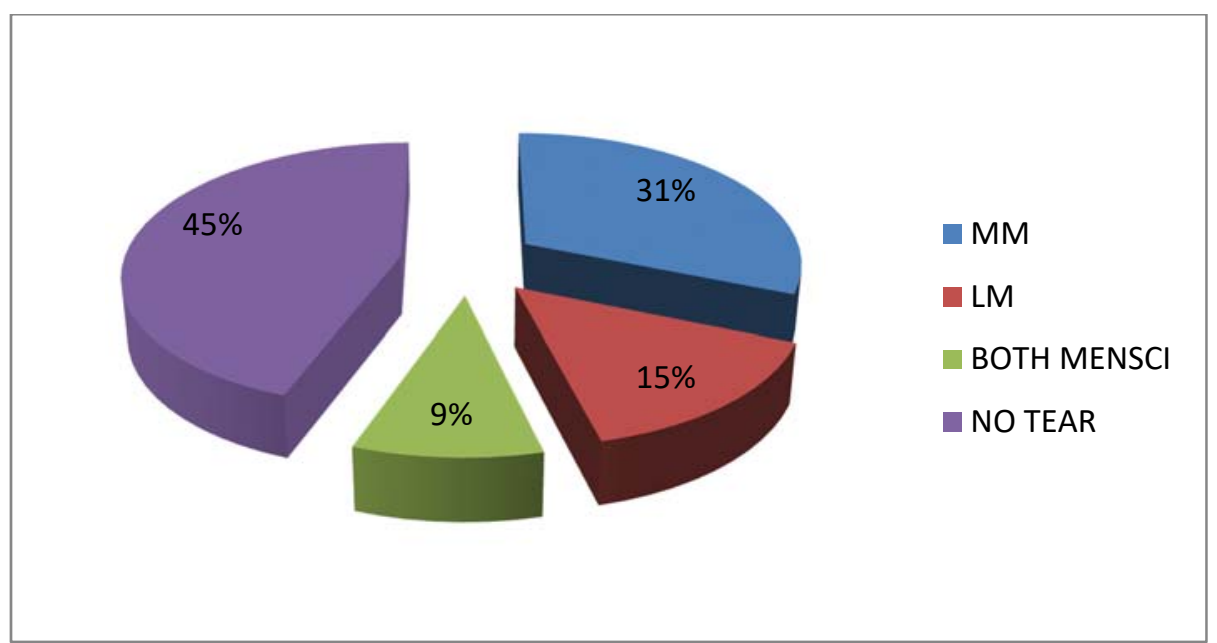

Fig.(4): Incidence of meniscal tears, MM: Medial meniscal tears, LM: Lateral meniscal tears. 


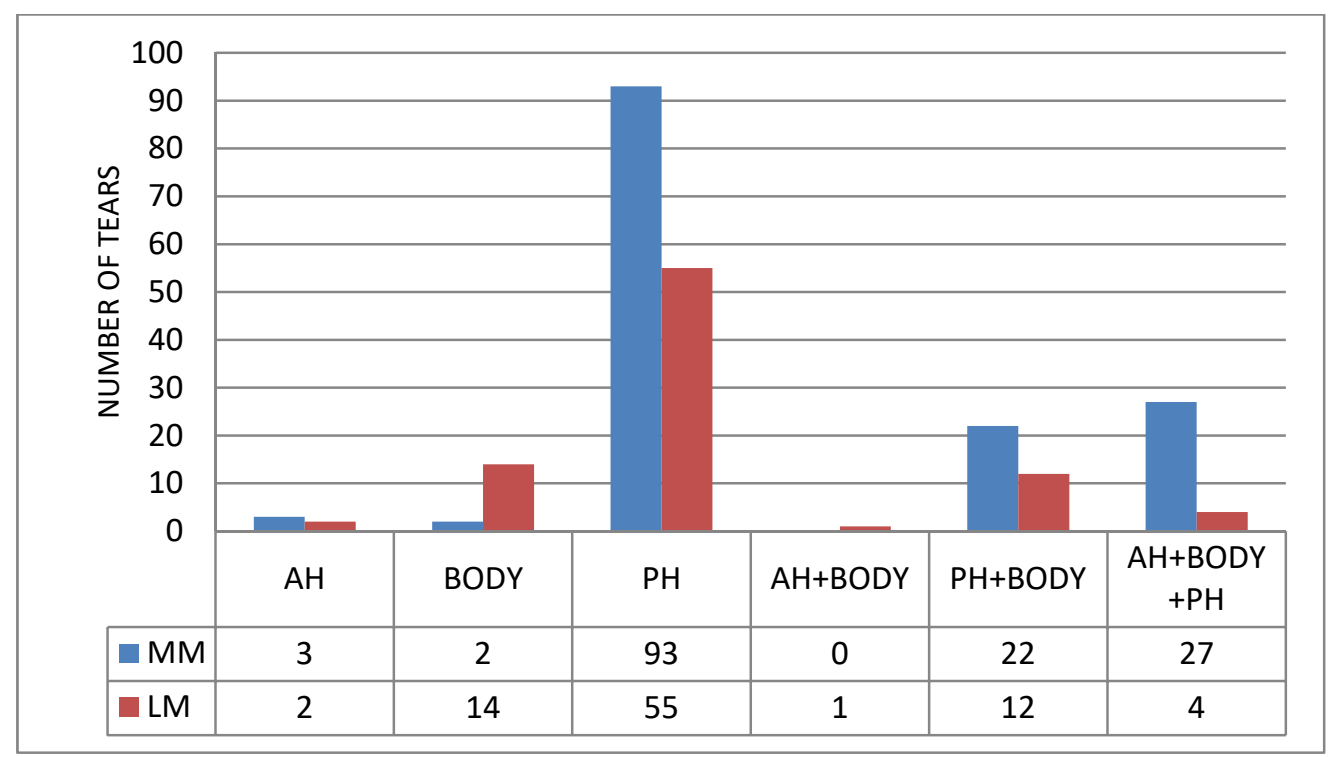

Fig.5: Distribution of the meniscal tears. AH: Anterior horn, PH: Posterior horn 




Fig. 6 a\&b: Types of the meniscal tears. a: MM tears, b: LM tears. 
Table (1): The means, standard deviations (SD) and ranges of all the variables for all patients. BMI: Body Mass Index, MTS: Medial Tibial Slope, LTS: Lateral Tibial Slope, TFI: Time From Injury.

\begin{tabular}{|c|c|c|c|c|c|}
\hline PARAMETER & AGE(years) & $\mathrm{BMI}\left(\mathrm{kg} / \mathrm{m}^{2}\right)$ & $\mathrm{MTS}\left(^{\circ}\right)$ & $\mathrm{LTS}\left({ }^{\circ}\right)$ & TFI(months) \\
\hline MEAN & 32.1 & 24.0 & 9.1 & 7.6 & 11.7 \\
\hline SD & 11.0 & 3.4 & 3.5 & 3.6 & 24.6 \\
\hline RANGE & $18.0-61.9$ & $17.5-37.6$ & $1-18.9$ & $-1.1-17.9$ & $0.37-256.4$ \\
\hline
\end{tabular}


Table (2): The distribution of the tear types between male and female patients.

\begin{tabular}{|c|c|}
\hline TEAR TYPE & MALE-FEMALE \% \\
\hline Vertical & $42.4 \%-7.3 \%$ \\
\hline Peripheral & $14.1 \%-7.3$ \\
\hline Horizontal & $4.7 \%-7.3 \%$ \\
\hline Flap & $3.8 \%-4.9 \%$ \\
\hline Bucket-handle & $9.4 \%-39.0 \%$ \\
\hline Degenerative & $0.9 \%-2.4 \%$ \\
\hline Oblique & $6.6 \%-4.9 \%$ \\
\hline Radial & $6.6 \%-9.7 \%$ \\
\hline Complex & $11.3 \%-14.6 \%$ \\
\hline
\end{tabular}

